\title{
Antimalarial Effects of Iranian Flora Artemisia sieberi on Plasmodium berghei In Vivo in Mice and Phytochemistry Analysis of Its Herbal Extracts
}

\author{
Hossein Nahrevanian,, ${ }^{1}$ Bayram Sheykhkanlooye Milan, ${ }^{2}$ Masoud Kazemi, ${ }^{3}$ \\ Reza Hajhosseini, ${ }^{2}$ Soudeh Soleymani Mashhadi, ${ }^{1}$ and Shahab Nahrevanian ${ }^{1,4}$ \\ ${ }^{1}$ Department of Parasitology, Pasteur Institute of Iran, Tehran, Iran \\ ${ }^{2}$ Division of Biochemistry, Department of Basic Sciences \& Agriculture, Payame Nour University, Tehran, Iran \\ ${ }^{3}$ Department of Applied Chemistry, Islamic Azad University, Qom Branch, Qom, Iran \\ ${ }^{4}$ Department of Molecular Biology, Umeå University, Umeå, Sweden
}

Correspondence should be addressed to Hossein Nahrevanian, mobcghn@gmail.com

Received 6 December 2011; Revised 31 December 2011; Accepted 5 January 2012

Academic Editor: Polrat Wilairatana

Copyright (C) 2012 Hossein Nahrevanian et al. This is an open access article distributed under the Creative Commons Attribution License, which permits unrestricted use, distribution, and reproduction in any medium, provided the original work is properly cited.

The aim of this study is pharmacochemistry of Iranian flora Artemisia sieberi and its antimalarial effects on Plasmodium berghei in vivo. This is the first application of $A$. sieberi for treatment of murine malaria. A. sieberi were collected at flowering stage from the Khorassan and Semnan provinces of Iran; the aerial parts were air-dried at room temperature and then powdered. The powder was macerated in methanol, filtered with Bokhner hopper and solvent was separated in rotary evaporator. Total herbal extract was subsequently processed for ether and chloroform extracts preparation. The toxicity of herbal extract was assessed on naive NMRI mice with high, average and low doses; then pathophysiological signs were assessed. Finally, the antimalarial efficacy was investigated on two groups of Plasmodium berghei infected mice. Percentage of parasitaemia and pathophysiology were also evaluated. The results of this assessment showed no toxicity even by high concentration of herbal extract. A significant reduction in percentage of parasitaemia was observed; no alterations of hepatosplenomegaly and body weight were indicated in study group. A. sieberi extracts showed antimalarial effects against murine malaria with some efficacies on reducing pathophysiology. However, there is requirement to find the major component of this herbal extract by further studies.

\section{Introduction}

Malaria is one of the most serious and widespread diseases encountered by human. It is an infectious disease caused by the parasite Plasmodia (P.) transmitted by the female anopheles. Four identified species of this parasite exist, which cause different types of human malaria [1]. Although all the four species of malaria parasites can infect humans and cause illness, only $P$. falciparum is known to be potentially life threatening and some of infected persons die, usually because of delayed treatment [2]; however, annual incidence of clinically new cases and mortality rates are decreasing [3-6].

As malaria vaccines remain problematic, chemotherapy still is the most important weapon in the fight against the disease [7]. The antimalarial drugs including chloroquine, quinine, mefloquine, pyrimethamine, and artemisinin are currently used in malaria treatment. Part of the reason for the failure to control malaria is the spread of resistance to firstline antimalarial drugs, cross-resistance between the limited number of drug families available, and some multidrug resistance [8]. Resistance has emerged to all classes of antimalarial drugs except artemisinin, an endoperoxide antimalarial drug derived as the active component of Artemisia annua, a herbal remedy used in Chinese folk medicine for 2000 years "qinghaosu" [9-12]. Artemisinin is a natural product and a powerful antimalarial drug with significant activities, which has high potency whilst possessing low toxicity during treatment of malaria [13-15].

The genus Artemisia has always been of great pharmaceutical interest and is useful in traditional medicines for 


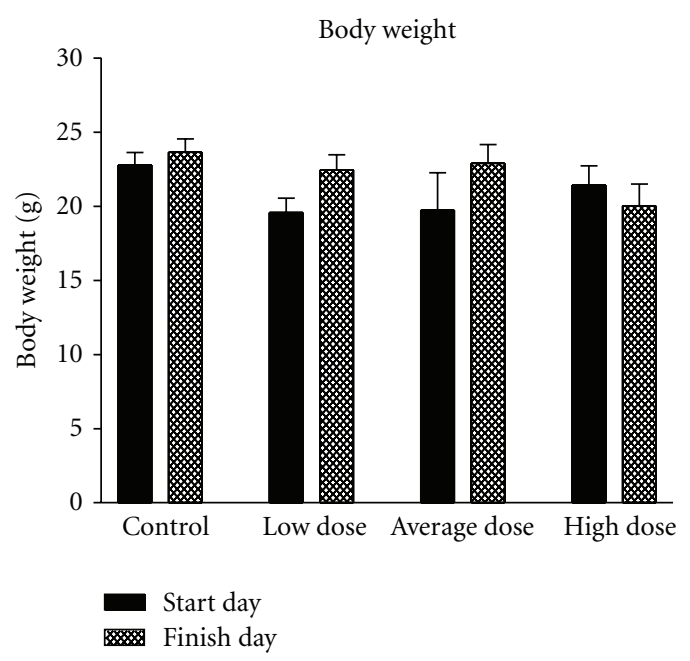

(a)

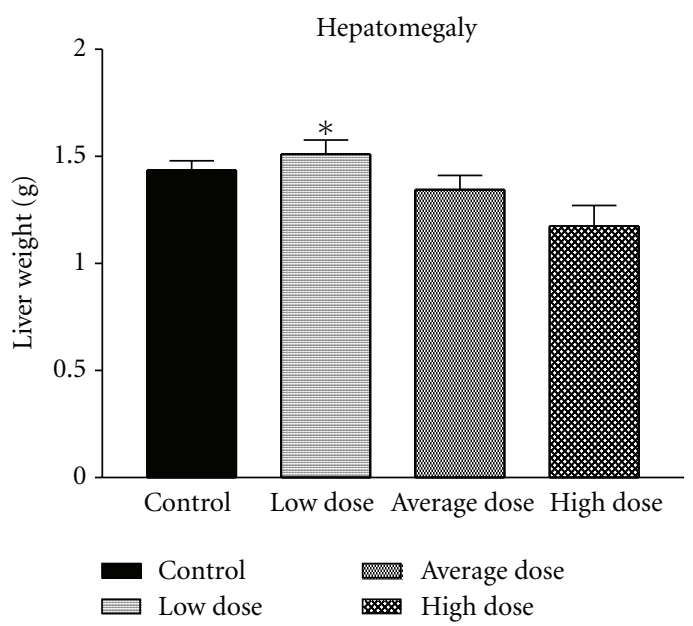

(c)

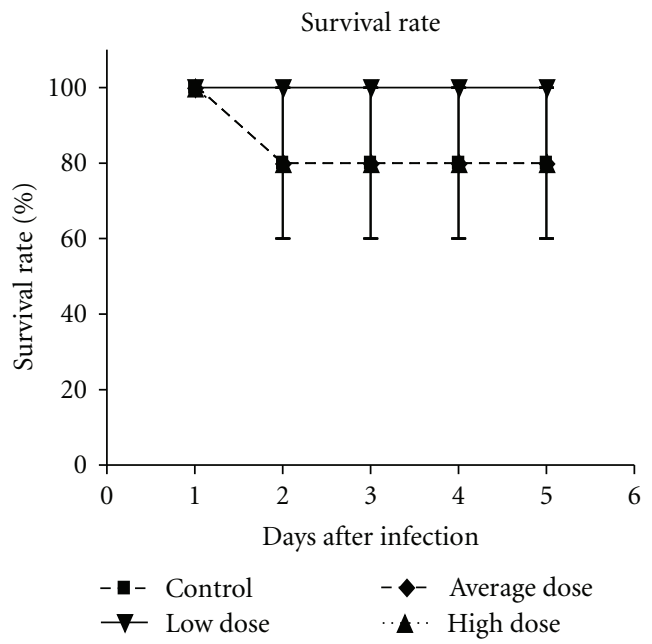

(b)

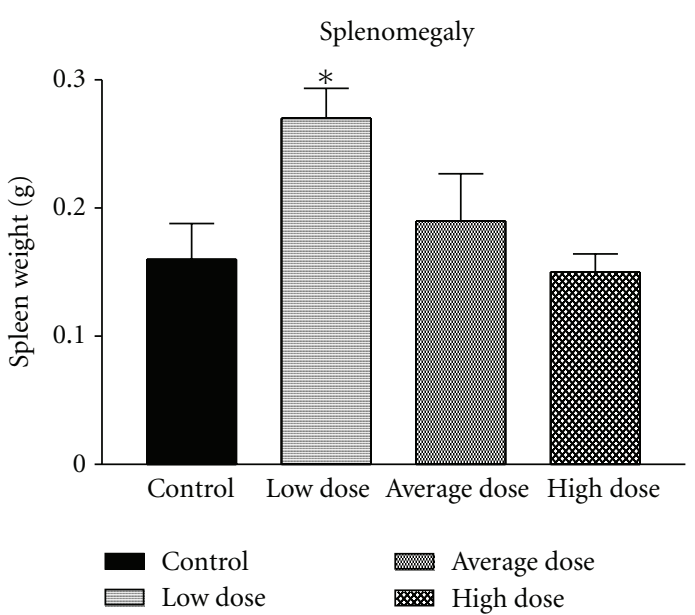

(d)

FIGURE 1: Toxicity assay induced by A. sieberi crude extract in naive animals. Pathophysiological alterations including body weight, survival rate, and hepato/splenomegaly were evaluated in control and test groups as toxicity assay induced by injection of low, average, and high doses of $A$. sieberi crude extract ( $n=5$ mice/group, Student's $t$-test, ${ }^{*} P<0.05$ ).

a treatment of the variety of diseases $[11,16,17]$. A. annua is presently being cultivated on a commercial scale in China and Vietnam for its antimalarial sesquiterpene lactone. The genus is of small herbs found in Northern temperate regions and belongs to the important family Compositae (Asteraceae), which comprises about 1,000 genera and over 20,000 species. Within this family, Artemisia is included into the family Anthemideae and comprises itself over 400 species, found in Europe and North America, but mainly are dominating Asia [18-20]. Among the Asian Artemisia flora, 150 species were recorded for China, 50 species reported in Japan, and 34 species found in Iran, of which may be endemic: A. melanolepis Boiss and A. kermanensis Pold [21], A. absinthium [22], A. annua [23], A. dracunculus [24], A. aucheri [25], A. haussknechtii Boiss [26], A. scoparia, A. sieberi [27], and A. sieberi Besser [28].

Pharmacochemical analysis of Artemisinin shows that the structure of this compound is rather unique among natural products as it contains the very unusual 1,2,4-trioxane ring system. It was sufficiently unusual that it was originally characterized as an ozonide until revised crystallographic analysis provided unambiguous structural elucidation [2933]. For a drug to be effective against the malaria parasite, it must reach the site of action in sufficient concentration and then interact with the receptors before it is either deactivated and/or eliminated by the host or the parasite. Pharmacologi$\mathrm{cal}$ and biochemical evaluation revealed that this compound was a blood schizonticide, preferentially imported into malaria infected erythrocytes via the parasitophorous duct [34] as it has been also shown in noninfectious diseases [35]. Due to complex chemical structure of artemisinin, the chemical synthesis of the molecule is complex, which results in very low yields, and the cost becomes prohibitory to use synthetic approach for its commercial production [36]. The mechanism of the action of Artemisinin remains a mystery; several candidates have been hypothesized as targets 


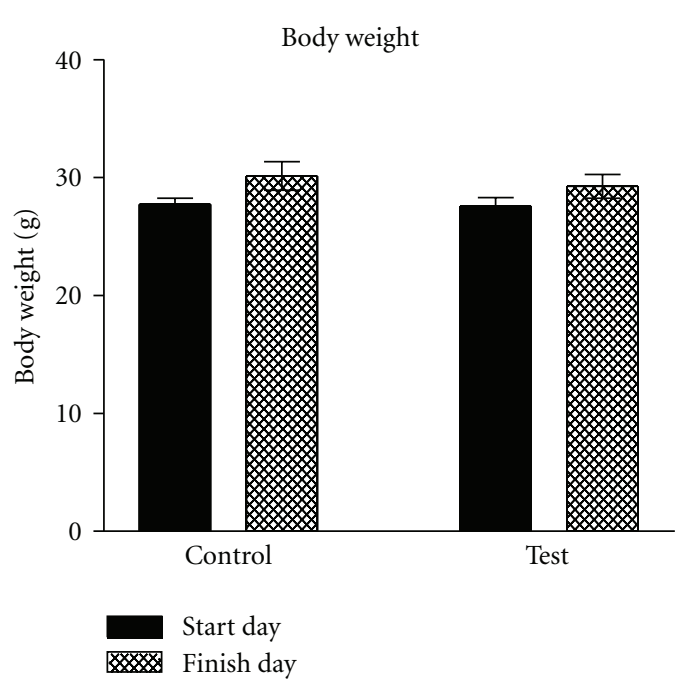

(a)

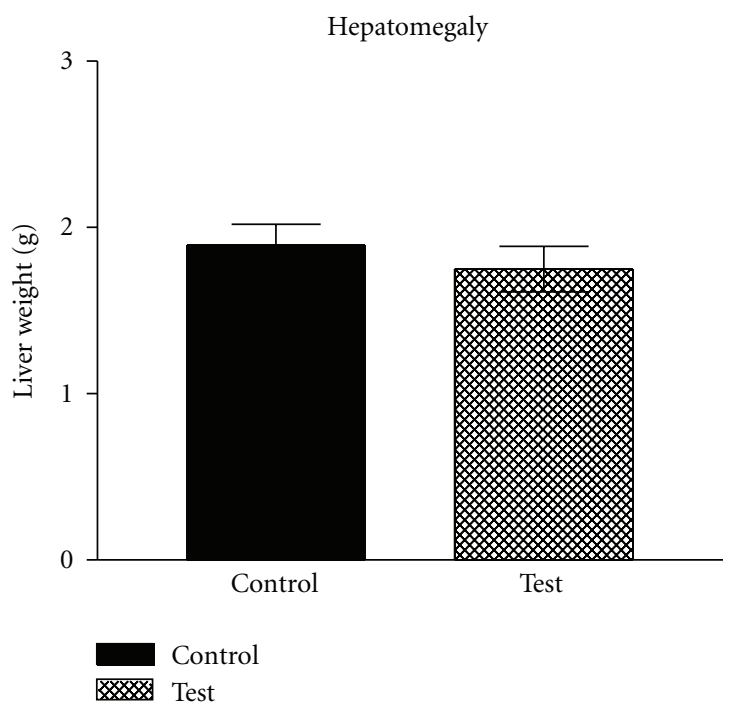

(c)

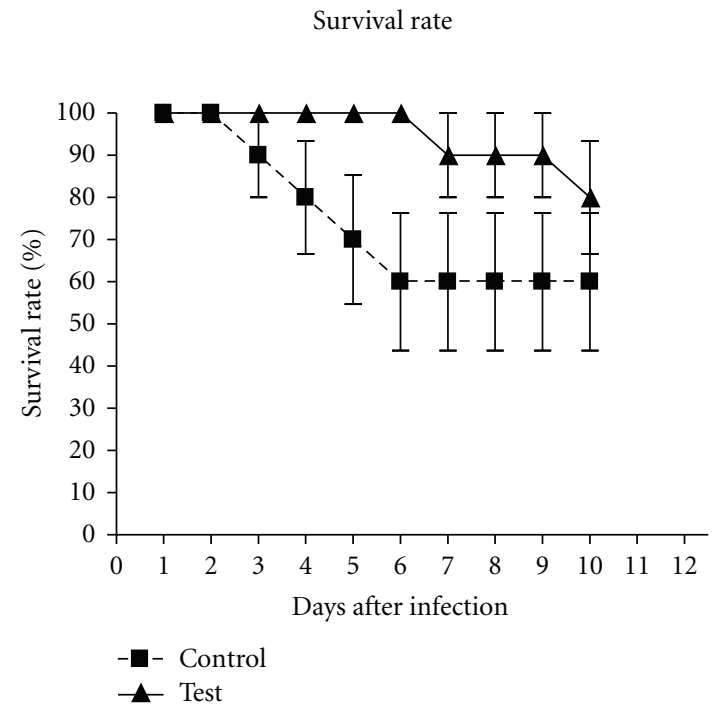

(b)

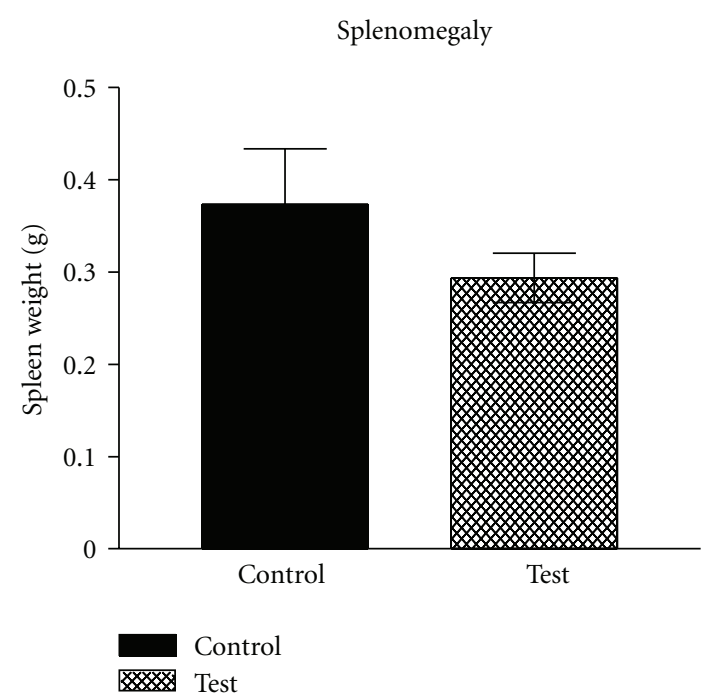

(d)

Figure 2: Toxicity assay induced by A. sieberi crude extract in malarial animals. Pathophysiological alterations including body weight, survival rate, and hepato/splenomegaly were evaluated as indices of toxicity by crude extract of $A$. sieberi in control and malarial groups (test, $A$. sieberi crude extract; control, drug vehicle; $n=10$ mice/day/group, Student's $t$-test).

of artemisinin, including iron, haem, and some parasite membrane proteins [37-39], PfATP6 [40]; however, none of these has been convincingly shown to be functionally relevant and need to be debated [41].

Pharmacochemistry and chemical analysis of different genus of Iranian Artemisia species has been studied, and the presence of variety of components including monoterpenes [42], sesquiterpenes $[43,44]$, sesquiterpene lactones $[45,46]$, and essential oils [47-51] was fully reported [22-28]. The aim of this study is pharmacochemistry of natural components of Iranian flora Artemisia sieberi and its antimalarial effects on Plasmodium berghei in vivo. This is the first application of $A$. sieberi for treatment of murine malaria so far.

\section{Materials and Methods}

2.1. Plant Samples. The aerial parts of A. sieberi were collected at flowering stage from the Khorassan and Semnan provinces of Iran. Voucher specimens were deposited and identified at the Herbarium of the Research Institute of Forests and Rangelands (RIFR), Tehran, Iran.

2.2. Herbal Extraction. The method was applied as described previously [52]. The aerial parts were air dried at room temperature then were powdered by mixer. The powder (140 gr) of A. sieberi was macerated in 1 lit methanol (Merck) and then kept for $72 \mathrm{~h}$ away from light and high temperature. It was filtered, evaporated, and dried by Rotary evaporator 


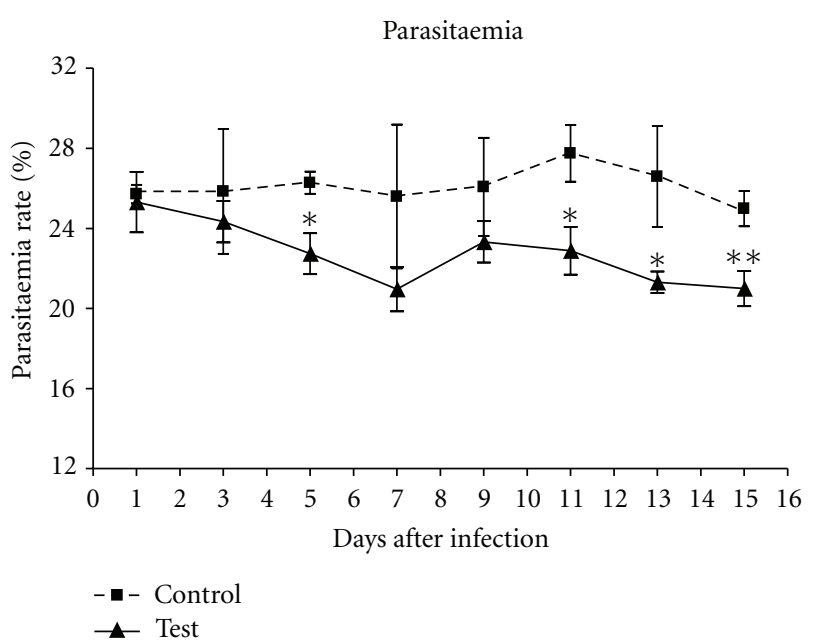

Figure 3: Percentage of parasitaemia in smears from blood of malarial mice. Smears were dried in air, fixed by methanol, and stained with Giemsa for counting of parasites inside red blood cells by light microscopy: test, A. sieberi crude extract; control, drug vehicle ( $n=10 \mathrm{mice} / \mathrm{day} /$ group, Student's $t$-test, ${ }^{*} P<0.05$, ** $P<0.01)$.

(Eyela, N-1000, Japan) and finally defatted in refrigerator. Wet weight of raw extract at the final step was $13.3 \mathrm{gr}$, and its color was dark green. The extract was kept in refrigerator until applied for the toxicity assay.

2.3. Ether and Chloroform Extraction of A. sieberi Compounds. Herbal extract was eluted with $300 \mathrm{~mL}$ n-hexane (Sigma, Co. India); two phases were separated; the lower hexane phase (non-polar compounds) was collected and kept at refrigerator for further experiment. The upper phase was eluted with $300 \mathrm{~mL}$ chloroform (Merck, India) 3 times; subsequently lower chloroform phase was collected, evaporated, and extracted. Higher methanol phase was then eluted with $300 \mathrm{~mL}$ diethyl ether (Merck, India) 3 times. Finally, ether phase was collected, evaporated, and extracted. It is suggested that semi polar components could be separated in these two chloroform and ether phases. The extracts were kept in refrigerator until used for injection in mice [52].

2.4. Animals. Male out bred NMRI (Naval Medical Research Institute) mice (supplied by the Laboratory Animal Department, Karaj Production and Research Complex, Pasteur Institute of Iran) were used in this study. The mice were 4-6 weeks of age and almost $20 \mathrm{~g}$ weight which were housed at room temperature $\left(20-23^{\circ} \mathrm{C}\right)$ on a $12 \mathrm{~h}$ light and $12 \mathrm{~h}$ dark cycle, with unlimited access to food and tap water.

2.5. Ethical Considerations. Experiments with animals were done according to the ethical standards formulated in the Declaration of Helsinki, and measures taken to protect animals from pain or discomfort. It has been approved by institutional ethical review board (Ethical Committee of the Pasteur Institute of Iran), in which the antimalarial test was done.

\subsection{Experiments and Groups}

(A) Toxicity Assay of A. sieberi Herbal Extract in Naïve Animals. In vivo toxicity was assessed by using herbal extract on naïve NMRI male mice. Animals were divided into four groups ( $n=5 \mathrm{mice} /$ group), including Group 1 (naïve), Group 2 (low dose), Group 3 (average dose), and Group 4 (high dose). According to several publications of this laboratory [51-54], in a blind experiment with no previous findings, three different concentrations ranging from 1 and $100 \mathrm{mg} / \mathrm{mL}$ can be used. A sample of herbal extract was suspended in ethanol and normal saline $(1: 9)$, then three different concentrations (low, average, and high doses) of herbal extracts including 1, 10, and $100 \mathrm{mg} / \mathrm{mL}$ were tested in vivo for their toxicity as test animals and a control group which was injected with drug vehicle. The parasite specificity of action was blood stage ring forms. Entire animals in all groups were injected with $200 \mu \mathrm{L}$ of related solutions subcutaneously (sc) once a day for 5 days.

(B) Antimalarial Effects of Herbal Extract on P. berghei Infected Mice. Following toxicity assay, the highest dose with the lowest toxicity of herbal extract $(100 \mathrm{mg} / \mathrm{mL}$ concentration) was selected to apply for its antimalarial activity on male NMRI mice infected with $P$. berghei. Animals were divided into two groups ( $n=10 \mathrm{mice} /$ group), including control and test; both groups were infected with murine malaria parasite, $P$. berghei. Drug vehicle and herbal extract were injected sc into control and test groups, respectively, once a day with $200 \mu \mathrm{L}$ of solutions for the period of 10 days.

(C) Antimalarial Effects of Ether and Chloroform Extracts on $P$. berghei Infected Mice. The antimalarial efficacy of ether and chloroform extracts was investigated on murine malaria $P$. berghei infected NMRI mice. Animals were divided into four groups ( $n=5 \mathrm{mice} /$ group), including ether extract control and test, chloroform extract control and test groups. Drug vehicle and extracts were injected sc into control and test groups, respectively, once a day with $200 \mu \mathrm{L}$ of solutions for the period of 14 days. Percentage of parasitaemia and pathophysiology were also evaluated.

2.7. Statistical Analysis. Values are presented as the mean \pm SEM for groups of $n$ samples. The significance of differences was determined by analysis of variances (ANOVA) and Student's $t$-test using Graph Pad Prism Software (Graph Pad, San Diego, CA, USA).

\section{Results}

Results of this experiment were classified in the following three steps including (A), (B), and (C).

(A) Toxicity Assay of A. sieberi Herbal Extract in Naïve Animals. No toxicity was observed in vivo even with high dose of $A$. sieberi total extract. Pathophysiological signs including body weight, survival rate, hepatomegaly, and splenomegaly represented no side effects of total extract (Figure 1). 


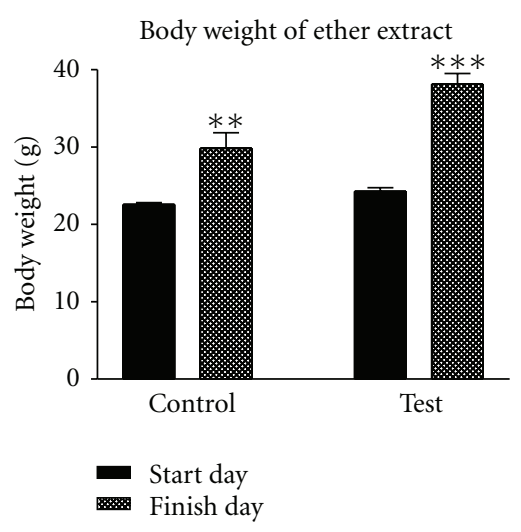

(a)

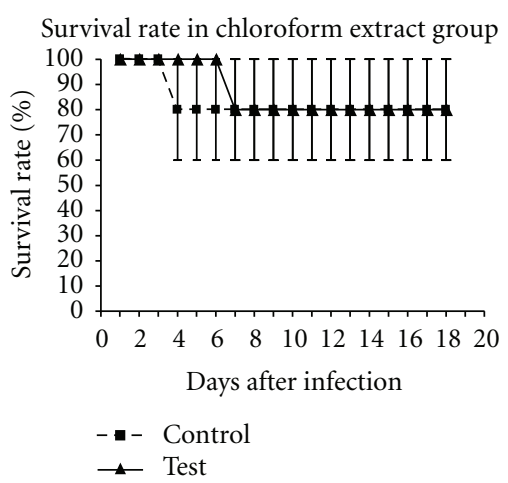

(d)

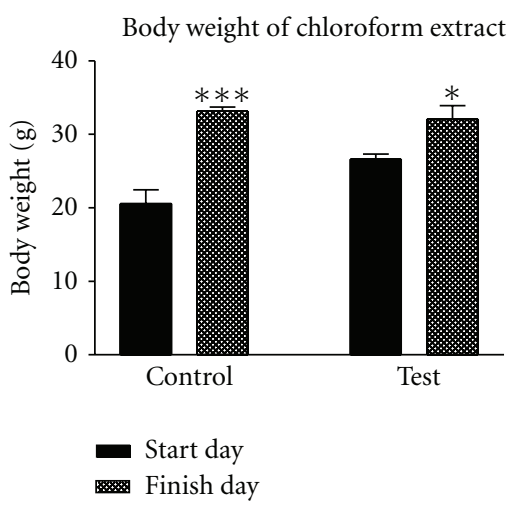

(b)

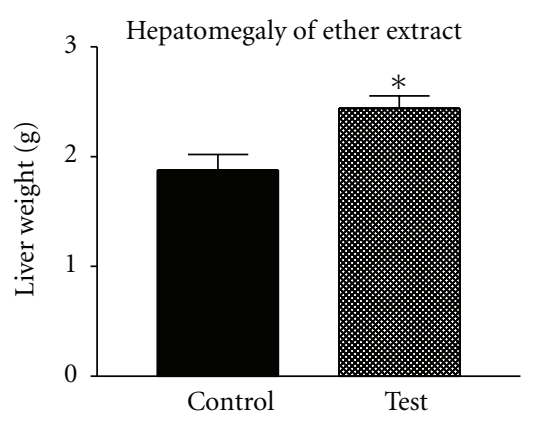

(e)

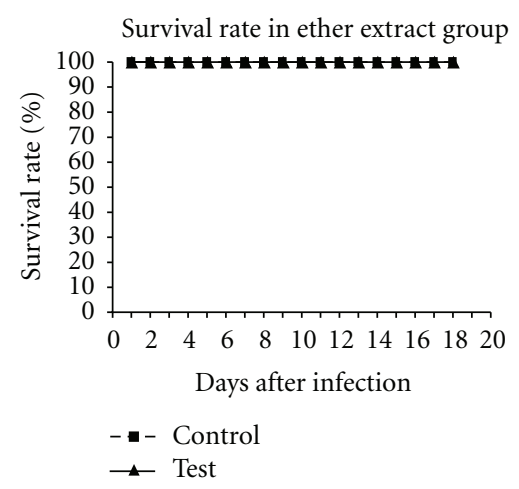

(c)

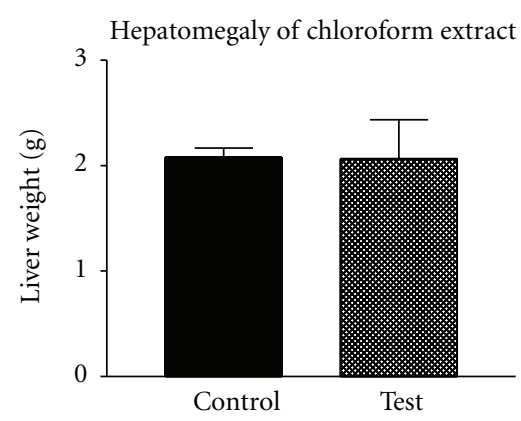

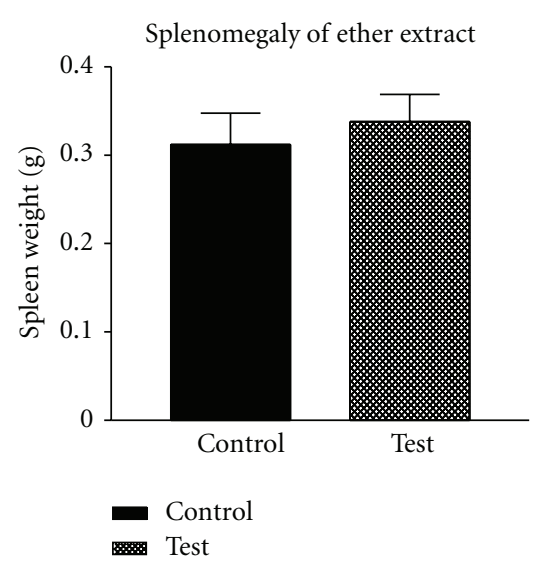

(g)

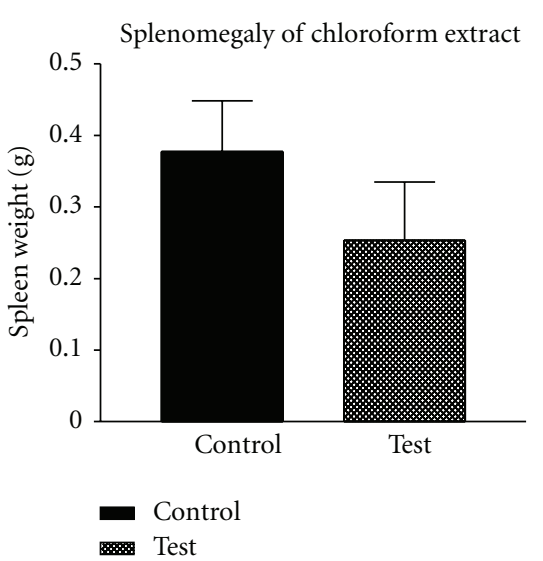

(h)

Figure 4: Pathophysiological alterations induced by A. sieberi ether and chloroform extracts in malarial animals. Pathophysiological alterations including body weight, survival rate, and hepato/splenomegaly were evaluated as indices of toxicity by ether and chloroform extracts of $A$. sieberi in control and malarial groups (test, A. sieberi ether and chloroform extracts; control, drug vehicle, $n=10$ mice/day/group, Student's $t$-test, $\left.{ }^{*} P<0.05,{ }^{* *} P<0.01,{ }^{* * *} P<0.001\right)$.

(B) Antimalarial Effects of Total Herbal Extract on P. berghei Infected Mice. No side effects on pathophysiology were represented by total extract in malarial mice (Figure 2). The results indicated significant effects of total extract on reducing parasitaemia in test group in comparison with control group (Figure 3).
(C) Antimalarial Effects of Ether and Chloroform Extracts in P. berghei Infected Mice. Low pathophysiological changes including survival rate and hepatomegaly were indicated after treatment in test groups when compared with those in control groups (Figure 4). The results indicated the inhibitory effects of the A. sieberi ether and chloroform 


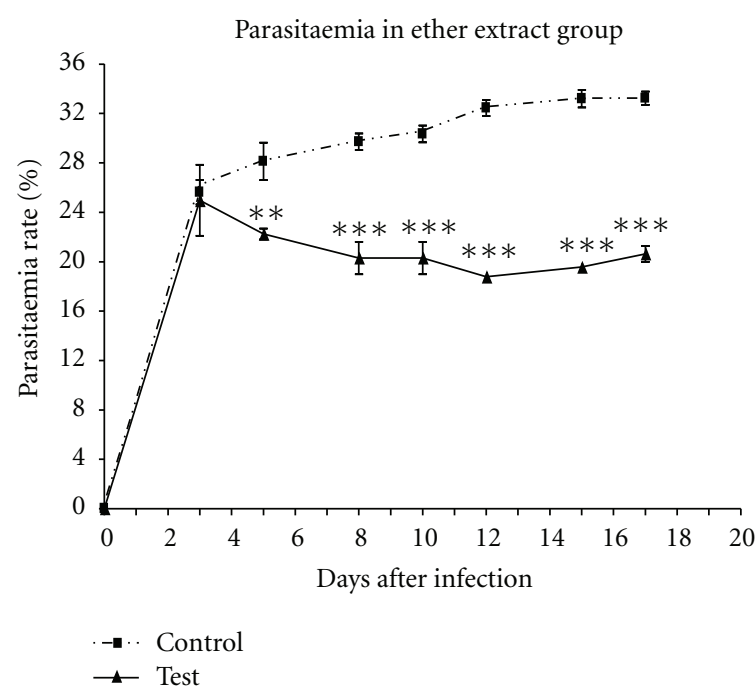

(a)

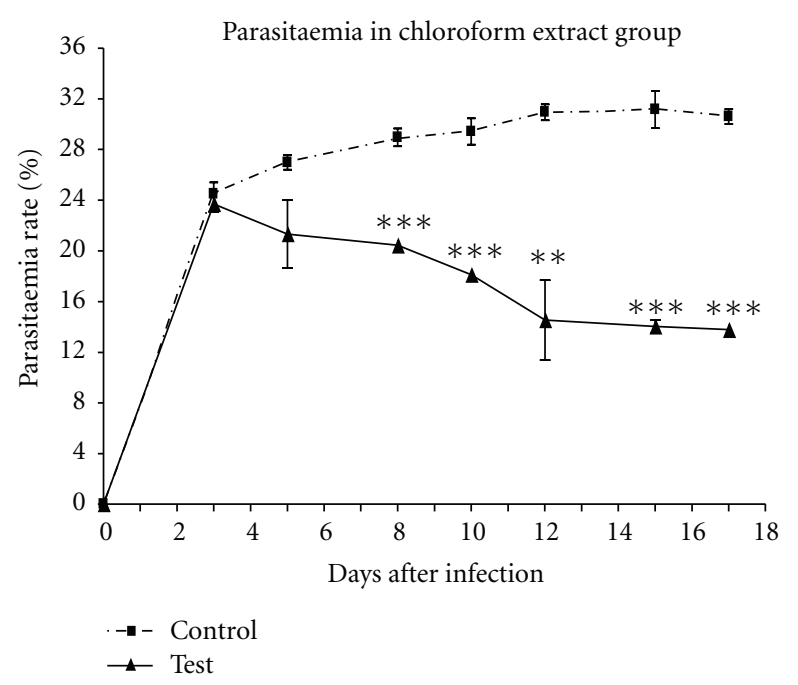

(b)

Figure 5: Percentage of parasitaemia induced by A. sieberi ether and chloroform extracts in malarial animals. Smears were dried in air, fixed by methanol, and stained with Giemsa for counting of parasites inside red blood cells by light microscopy (test, A. sieberi ether and chloroform extracts; control, drug vehicle, $n=10$ mice/day/group, Student's $t$-test, ${ }^{* *} P<0.01,{ }^{* * *} P<0.001$ ).

extracts on malaria by high reduction degree of parasitaemia (Figure 5).

\section{Discussion}

Although various species of the genus Artemisia were used for their pharmacological, antimicrobial, and antioxidant activity, only few species of this genus including A. scoparia, A. sieberi, and A. aucheri are widely distributed in desert area of Iran. This investigation is the first report on application of A. sieberi extracts on the treatment of murine malaria.

The results of this assessment showed no toxicity even with high concentration of herbal extract, which confirms its minimal side effects. In spite of less efficacy of crude extract of herb, ether and chloroform extracts were isolated from A. sieberi and were successfully tested in P. berghei murine malaria. Although a significant reduction was observed in the percentage of parasitaemia, no pathophysiological alterations were indicated in host hepato/splenomegaly and in body weight. The microscopic examination of Giemsastained slides showed a virtual absence of blood stage of the murine malaria treated with this herbal extracts. These observations suggest that the active constituents in the extract may be cytotoxic for P. berghei, thereby inhibiting their development to the erythrocytic stage.

In authors' previous publications [52-56], antimalarial effects of different Iranian flora of Artemisia herbal extracts including A. turanica A. khorassanica, A. diffusa, A. absinthi$u m$, and their effective agent (Tehranolide) against malaria and/or leishmania were successfully evaluated. The route of inoculation is important factor to determine herbal efficacy. Although subcutaneous injection was used in this study, other routes may be recommended for future studies. In addition to authors' previous publications [52-56], data of this study specifically indicated the inhibitory effects of the A. sieberi ether and chloroform extracts on the developmental stages of $P$. berghei by decreasing parasitaemia. The microscopic examination of Giemsa-stained slides showed a virtual absence of blood stage of the murine malaria treated with these herbal extracts. These observations suggest that the active constituents in the extract may be cytotoxic for $P$. berghei, thereby inhibiting their development to the erythrocytic stage. Although this study confirmed antimalarial effects of $A$. sieberi extracts against murine malaria in vivo during infection; however, there are more efficacies on pathophysiological symptoms by this medication. These observations provide the basis for the traditional use of this herb in treatments of malaria disease.

Conclusively, the A. sieberi extract had antimalarial effects against murine malaria in vivo. Moreover, some efficacies are indicated on reducing pathophysiological symptoms by this medication. However, there is requirement to find the major component of this herbal extract by further studies. More investigations are required on different Plasmodia and animal hosts to clarify details of antimalarial effects of $A$. sieberi and analysis of its natural components.

\section{Conflict of Interests}

The authors declare that they have no conflict of interests.

\section{Authors' Contribution}

H. Nahrevanian and M. Kazemi conceptualized and designed the study. B. S. Milan conducted the daily monitoring of malaria parasitaemia and laboratory investigations. S. S. Mashhadi involved other laboratory assays and animal working. S. Nahrevanian and R. Hajhosseini involved in statistical analysis, preparation, and proofreading of the paper. 


\section{Acknowledgments}

This work was funded by the Department of Parasitology, Pasteur Institute of Iran and collaboration with Department of Applied Chemistry, Islamic Azad University, Qom Branch, Qom, Iran. This study has been involved an M.S. student thesis from Payame Noor University of Tehran centre, Iran under corresponding author supervision.

\section{References}

[1] J. G. Hardman and L. E. Limbird, "Drugs used in the chemotherapy of malaria," in The Goodman and Gilman's Pharmacological Bases of Therapeutics, L. Brunton, J. Lazo, and K. Parker, Eds., pp. 1069-1100, McGraw-Hill, New York, NY, USA, 10th edition, 2001.

[2] I. T. Peter and V. K. Anatoli, The Current Global Malaria Situation; Malaria Parasite Biology, Pathogenesis and Protection, ASM Press, Washington, DC, USA, 1st edition, 1998.

[3] M. S. Alilio, I. C. Bygbjerg, and J. G. Breman, "Are multilateral malaria research and control programs the most successful? Lessons from the past 100 years in Africa," American Journal of Tropical Medicine and Hygiene, vol. 71, supplement 2, pp. 268-278, 2004.

[4] L. H. Miller, M. F. Good, and G. Million, "Malaria pathogenesis," Science, vol. 264, no. 5167, pp. 1878-1883, 1994.

[5] C. M. Morel, "Reaching maturity-25years of the TDR," Parasitology Today, vol. 16, no. 12, pp. 522-528, 2000.

[6] A. F. David, J. R. Philip, L. C. Simon, B. Reto, and N. Solomon, "Antimalarial drug discovery: efficacy models for compound screening," Nature Reviews Drug Discovery, vol. 3, no. 6, pp. 509-520, 2004.

[7] S. Turschner and T. Efferth, "Drug resistance in plasmodium: natural products in the fight against malaria," Mini-Reviews in Medicinal Chemistry, vol. 9, no. 2, pp. 206-214, 2009.

[8] P. Olliaro, J. Cattani, and D. Wirth, "Malaria, the submerged disease," Journal of the American Medical Association, vol. 275, no. 3, pp. 230-233, 1996.

[9] N. J. White and P. L. Olliaro, "Strategies for the prevention of antimalarial drug resistance: rationale for combination chemotherapy for malaria," Parasitology Today, vol. 12, no. 10, pp. 399-401, 1996.

[10] S. P. He, G. Y. Tan, G. Li et al., "Development of a sensitive monoclonal antibody-based enzyme-linked immunosorbent assay for the antimalaria active ingredient artemisinin in the Chinese herb Artemisia annua L," Analytical and Bioanalytical Chemistry, vol. 393, no. 4, pp. 1297-1303, 2009.

[11] J. A. Willoughby Sr., S. N. Sundar, M. Cheung, A. S. Tin, J. Modiano, and G. L. Firestone, "Artemisinin blocks prostate cancer growth and cell cycle progression by disrupting $\mathrm{Sp} 1$ interactions with the cyclin-dependent kinase-4 (CDK4) promoter and inhibiting CDK4 gene expression," The Journal of Biological Chemistry, vol. 284, no. 4, pp. 2203-2213, 2009.

[12] P. R. Arsenault, K. K. Wobbe, and P. J. Weathers, "Recent advances in artemisinin production through heterologous expression," Current Medicinal Chemistry, vol. 15, no. 27, pp. 2886-2896, 2008.

[13] D. L. Klayman, A. J. Lin, N. Acton et al., "Isolation of artemisinin (qinghaosu) from Artemisia annua growing in the United States," Journal of Natural Products, vol. 47, no. 4, pp. 715-717, 1984.

[14] D. K. Ro, M. Ouellet, E. M. Paradise et al., "Induction of multiple pleiotropic drug resistance genes in yeast engineered to produce an increased level of anti-malarial drug precursor, artemisinic acid," BMC Biotechnology, vol. 8, article 83, 2008.

[15] S. de Ridder, F. van der Kooy, and R. Verpoorte, "Artemisia апnиa as a self-reliant treatment for malaria in developing countries," Journal of Ethnopharmacology, vol. 120, no. 3, pp. 302-314, 2008.

[16] H. A. Arab, S. Rahbari, A. Rassouli, M. H. Moslemi, and F. Khosravirad, "Determination of artemisinin in Artemisia sieberi and anticoccidial effects of the plant extract in broiler chickens," Tropical Animal Health and Production, vol. 38, no. 6, pp. 497-503, 2006.

[17] M. R. Romero, M. A. Serrano, M. Vallejo, T. Efferth, M. Alvarez, and J. J. Marin, "Antiviral effect of artemisinin from Artemisia annua against a model member of the Flaviviridae family, the bovine viral diarrhoea virus (BVDV)," Planta Medica, vol. 72, no. 13, pp. 1169-1174, 2006.

[18] V. H. Heywood and C. J. Humphries, "Anthemideae systematic review," in The Biology and Chemistry of the Compositae, V. H. Heywood, J. B. Harbord, and B. L. Turner, Eds., chapter 31, pp. 852-888, Academic Press, London, UK, 2nd edition, 1977.

[19] N. J. White, "Qinghaosu (artemisinin): the price of success," Science, vol. 320, no. 5874, pp. 330-334, 2008.

[20] C. Liu, Y. Zhao, and Y. Wang, "Artemisinin: current state and perspectives for biotechnological production of an antimalarial drug," Applied Microbiology and Biotechnology, vol. 72, no. 1, pp. 11-20, 2006.

[21] K. H. Rechinger, "Artemisia in flora iranica," in Compositae, K. H. Rechinger and I. C. Hedge, Eds., no. chapter 158, p. 214, Akademische Druck and Verlagsanatalt, Graz, Austria, 1986.

[22] A. Rezaeinodehi and S. Khangholi, "Chemical composition of the essential oil of Artemisia absinthium growing wild in Iran," Pakistan Journal of Biological Sciences, vol. 11, no. 6, pp. 946949, 2008.

[23] S. Khangholil and A. Rezaeinodehi, "Effect of drying temperature on essential oil content and composition of sweet wormwood (Artemisia annua) growing wild in Iran," Pakistan Journal of Biological Sciences, vol. 11, no. 6, pp. 934-937, 2008.

[24] A. Maleki and M. A. Zarasvand, "Heavy metals in selected edible vegetables and estimation of their daily intake in Sanandaj, Iran," Southeast Asian Journal of Tropical Medicine and Public Health, vol. 39, no. 2, pp. 335-340, 2008.

[25] S. Asgary, N. J. Dinani, H. Madani, and P. Mahzouni, "Ethanolic extract of Artemisia aucheri induces regression of aorta wall fatty streaks in hypercholesterolemic rabbits," Pharmazie, vol. 63, no. 5, pp. 394-397, 2008.

[26] M. Jalali Heravi and H. Sereshti, "Determination of essential oil components of Artemisia haussknechtii Boiss. using simultaneous hydrodistillation-static headspace liquid phase microextraction-gas chromatography mass spectrometry," Journal of Chromatography A, vol. 1160, no. 1-2, pp. 81-89, 2007.

[27] M. Farzaneh, M. Ahmadzadeh, J. Hadian, and A. S. Tehrani, "Chemical composition and antifungal activity of the essential oils of three species of Artemisia on some soil-borne phytopathogens," Communications in Agricultural and Applied Biological Sciences, vol. 71, no. 3, part B, pp. 1327-1333, 2006.

[28] R. Bagheri, M. R. Chaichi, M. Mohseni-Saravi, G. R. Amin, and G. Zahedi, "Grazing affects essential oil compositions of Artemisia sieberi Besser," Pakistan Journal of Biological Sciences, vol. 10, no. 5, pp. 810-813, 2007.

[29] J. D. Gu, K. X. Chena, H. L. Jianga, and J. Leszczynski, “A model molecule study of the O-centered and the C-centered free radical intermediates of artemisinin," Journal of Molecular Structure, vol. 491, no. 1-3, pp. 57-66, 1999. 
[30] J. D. Gu, K. X. Chen, H. L. Jiang, and J. Leszczynski, "The radical transformation in artemisinin: a DFT study," Journal of Physical Chemistry A, vol. 103, no. 46, pp. 9364-9369, 1999.

[31] P. C. Castilho, S. C. Gouveia, and A. I. Rodrigues, "Quantification of artemisinin in Artemisia annua extracts by $1 \mathrm{H}-\mathrm{NMR}$," Phytochemical Analysis, vol. 19, no. 4, pp. 329-334, 2008.

[32] C. Ma, H. Wang, X. Lu, H. Li, B. Liu, and G. Xu, "Analysis of Artemisia annua L. volatile oil by comprehensive twodimensional gas chromatography time-of-flight mass spectrometry," Journal of Chromatography A, vol. 1150, no. 1-2, pp. 50-53, 2007.

[33] R. K. Haynes, "From artemisinin to new artemisinin antimalarials: biosynthesis, extraction, old and new derivatives, stereochemistry and medicinal chemistry requirements," Current Topics in Medicinal Chemistry, vol. 6, no. 5, pp. 509-537, 2006.

[34] N. Vyas, B. A. Avery, M. A. Avery, and C. M. Wyandt, "Carrier-mediated partitioning of artemisinin into plasmodium falciparum-infected erythrocytes," Antimicrobial Agents and Chemotherapy, vol. 46, no. 1, pp. 105-109, 2002.

[35] S. R. Meshnick, T. E. Taylor, and S. Kamchonwongpaisan, "Artemisinin and the antimalarial endoperoxides: from herbal remedy to targeted chemotherapy," Microbiological Reviews, vol. 60, no. 2, pp. 301-315, 1996.

[36] A. Bhattacharya, L. C. Mishra, and V. K. Bhasin, "In vitro activity of artemisinin in combination with clotrimazole or heat-treated amphotericin B against Plasmodium falciparum," American Journal of Tropical Medicine and Hygiene, vol. 78, no. 5, pp. 721-728, 2008.

[37] S. R. Meshnick, "Artemisinin: mechanisms of action, resistance and toxicity," International Journal for Parasitology, vol. 32, no. 13, pp. 1655-1660, 2002.

[38] W. Asawamahasakda, A. Benakis, and S. R. Meshnick, "The interaction of artemisinin with red cell membranes," Journal of Laboratory and Clinical Medicine, vol. 123, no. 5, pp. 757$762,1994$.

[39] J. Bhisutthibhan, X. Q. Pan, P. A. Hossler et al., "The Plasmodium falciparum translationally controlled tumor protein homolog and its reaction with the antimalarial drug artemisinin," The Journal of Biological Chemistry, vol. 273, no. 26, pp. 16192-16198, 1998.

[40] U. Eckstein-Ludwig, R. J. Webb, I. D. A. van Goethem et al., "Artemisinins target the SERCA of Plasmodium falciparum," Nature, vol. 424, no. 6951, pp. 957-961, 2003.

[41] O. Mercereau-Puijalon and T. Fandeur, "Antimalarial activity of artemisinins: identification of a novel target?" The Lancet, vol. 362, no. 9401, pp. 2035-2036, 2003.

[42] A. Rustaiyan, A. Bamoniri, M. Raffatrad, J. Jakupovic, and F. Bohlman, "Eudesmane derivatives and highly oxygenated monoterpenes from Iranian Artemisia species," Phytochemistry, vol. 26, no. 8, pp. 2307-2310, 1987.

[43] P. Weyerstahl, S. Schneider, H. Marschall, and A. Rustaiyan, "The essential oil of Artemisia sieberi," Flavour and Fragrance Journal, vol. 8, pp. 139-45, 1993.

[44] P. Weyerstahl, S. Schneider, H. Marschall, and A. Rustaiyan, "Terpenes and terpene derivatives, XXXI. New bisabolene derivatives and a salsolene ketone from Artemisia sieberi Bess," Liebigs Annalen der Chemie, vol. 1993, no. 2, pp. 111-116, 1993.

[45] A. Rustaiyan, H. Sigari, J. Jakupovic, and M. Grenz, "A sesquiterpene lactone from Artemisia diffusa," Phytochemistry, vol. 28, no. 10, pp. 2723-2725, 1989.

[46] A. Rustaiyan, K. Zare, M. T. Ganj, and H. A. Sadri, "A melampolide and two dihydro artemorin derivatives from
Artemisia gypsacea," Phytochemistry, vol. 28, no. 5, pp. 15351536, 1989.

[47] A. Rustaiyan, S. Balalaei, F. Mohammadi, S. Masoudi, and M. Yari, "Comparison of the volatile oils of Artemisia santolina Schrenk and Artemisia gypsacea Krasch M. Pop. et Lincz. ex Poljak, from Iran,” Journal of Essential Oil Research, vol. 12, no. 3, pp. 330-332, 2000.

[48] A. Rustaiyan, H. Komeilizadeh, S. Masoudi et al., "Composition of the volatile oil of Artemisia deserti Krash. and Artemisia oliveriana J. Gayex DC. from Iran," Iranian Journal of Science and Technology, vol. 11, pp. 213-215, 2000.

[49] F. Sefidkon, A. Jalili, and T. Mirhaji, "Essential oil composition of three Artemisia spp. from Iran," Flavour and Fragrance Journal, vol. 17, no. 2, pp. 150-152, 2002.

[50] K. Morteza-Semnani, M. Akbarzadeh, and K. Moshiri, "Essential oil composition of Artemisia fragrans Willd. from Iran," Flavour and Fragrance Journal, vol. 20, no. 3, pp. 330-331, 2005.

[51] F. Nematollahi, A. Rustaiyan, K. Larijani, M. Nadimi, and S. Masoudi, "Essential oil composition of Artemisia biennis Willd. and pulicaria undulata (L.) C.A. Mey., two compositae herbs growing wild in Iran," Journal of Essential Oil Research, vol. 18, no. 3, pp. 339-341, 2006.

[52] H. Nahrevanian, F. Aboufazeli, M. Kazemi, R. Hajihosseini, and S. Naeimi, "Phytochemical evaluation and antimalarial effects of Artemisia turanica herbal extracts as an Iranian flora on Plasmodium berghei in vivo," Journal of Natural Remedies, vol. 11, no. 2, pp. 167-176, 2011.

[53] H. Nahrevanian, B. Esmaeili, M. Kazemi, H. Nazem, and M. Amini, "In vivo antimalarial effects of Iranian flora Artemisia khorassanica against Plasmodium berghei and pharmacochemistry of its natural components," Iranian Journal of Parasitology, vol. 5, no. 1, pp. 6-19, 2010.

[54] A. Rustaiyan, H. Nahrevanian, and M. Kazemi, "A new antimalarial agent; effect of extracts of Artemisia diffusa against Plasmodium berghei," Pharmacognosy Magazine, vol. 4, no. 17, pp. 1-7, 2009.

[55] A. Rustaiyan, H. Nahrevanian, and M. Kazemi, "Isolation of Artediffusin (Tehranolide) as a new antimalarial agent," Asian Journal of Chemistry, vol. 23, no. 11, pp. 4810-4814, 2011.

[56] B. Esfandiari, M. R. Youssefi, M. Keighobadi, and H. Nahrevanian, "In vivo evaluation of anti-parasitic effects of Artemisia absinthium extracts on Syphacia parasite," The Internet Journal of Parasitic Diseases, vol. 2, no. 2, pp. 1-5, 2007. 


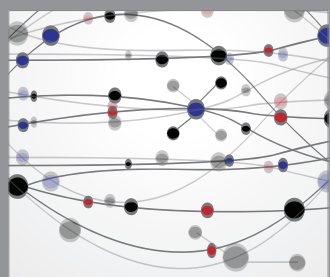

The Scientific World Journal
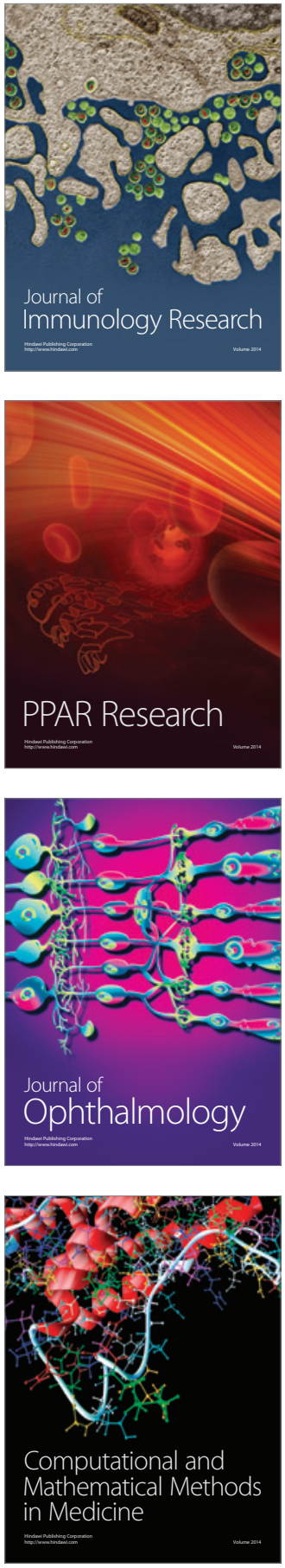

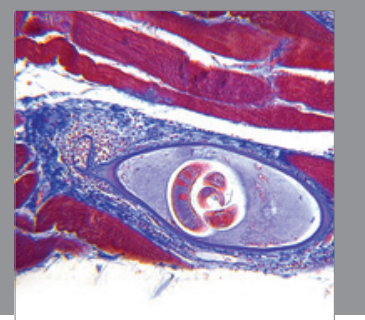

Gastroenterology

Research and Practice
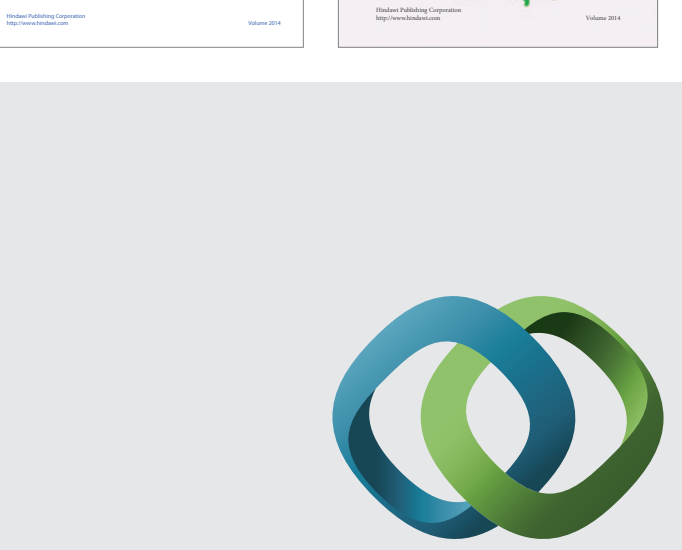

\section{Hindawi}

Submit your manuscripts at

http://www.hindawi.com
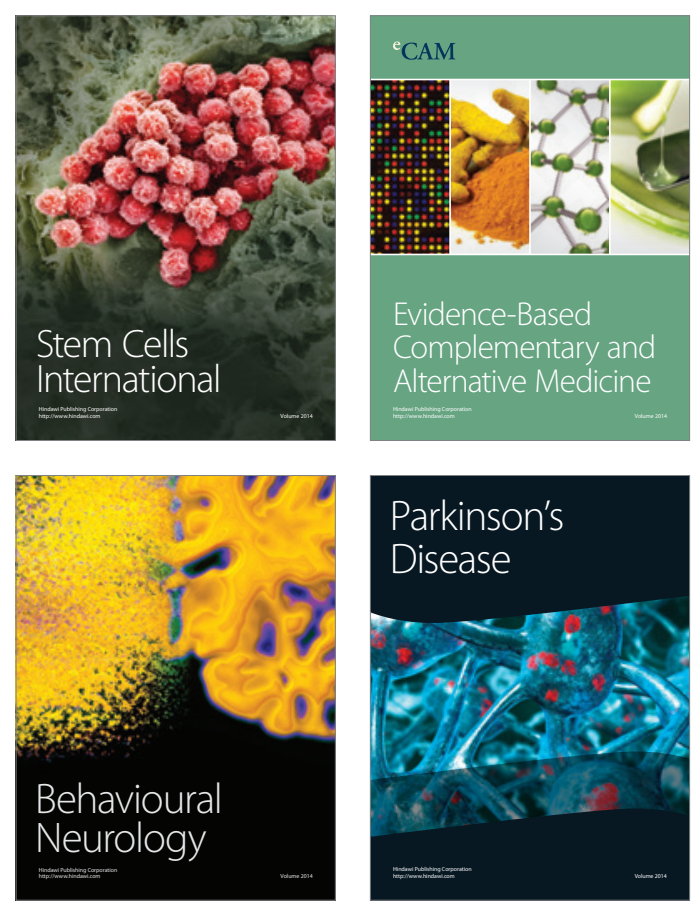

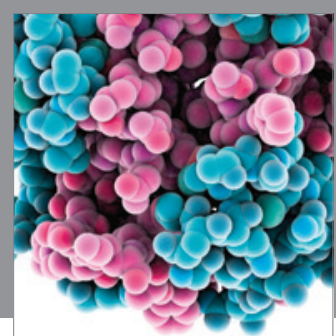

Journal of
Diabetes Research

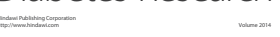

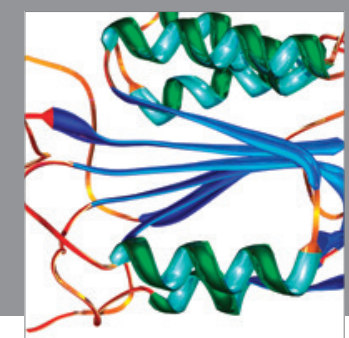

Disease Markers
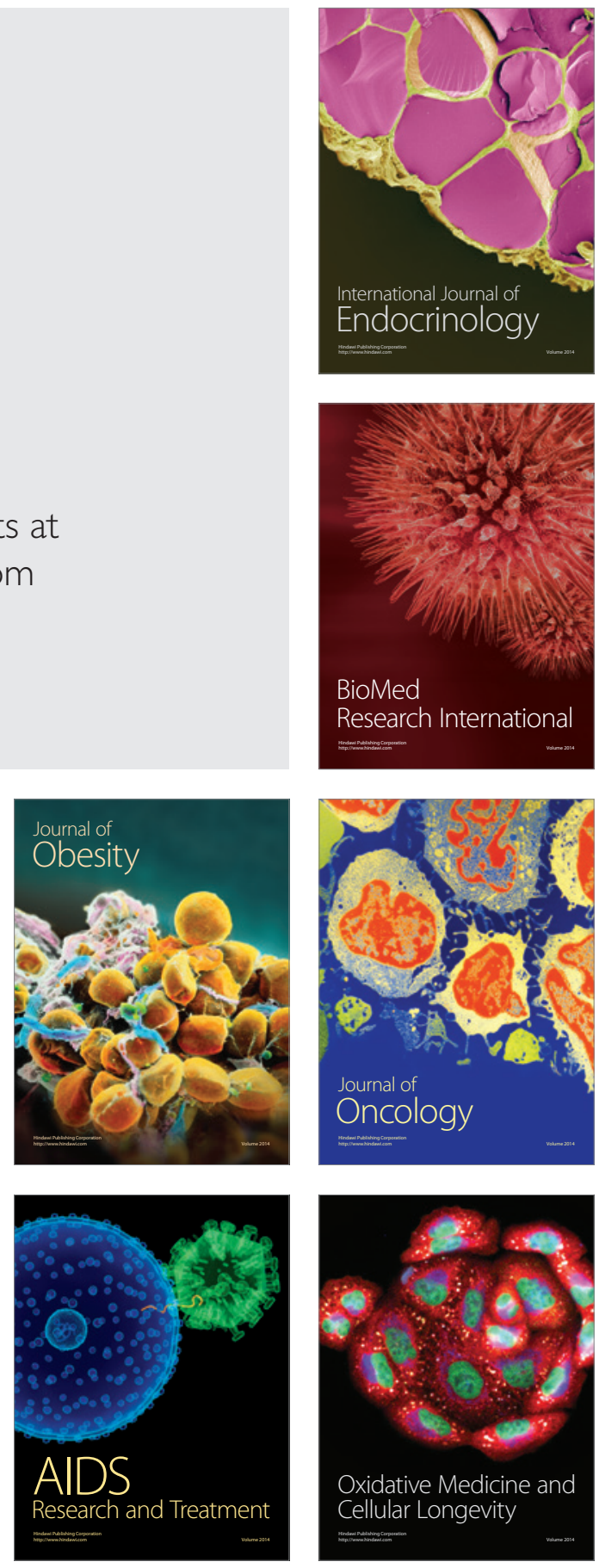